\title{
Nitrogen metabolism and remobilization during senescence
}

\author{
Stefan Hörtensteiner and Urs Feller ${ }^{1}$ \\ Institute of Plant Sciences, University of Bern, Altenbergrain 21, CH-3013 Bern, Switzerland
}

Received 18 July 2001; Accepted 5 November 2001

\begin{abstract}
Senescence is a highly organized and well-regulated process. As much as $75 \%$ of total cellular nitrogen may be located in mesophyll chloroplasts of $\mathrm{C}_{3}$-plants. Proteolysis of chloroplast proteins begins in an early phase of senescence and the liberated amino acids can be exported to growing parts of the plant (e.g. maturing fruits). Rubisco and other stromal enzymes can be degraded in isolated chloroplasts, implying the involvement of plastidial peptide hydrolases. Whether or not ATP is required and if stromal proteins are modified (e.g. by reactive oxygen species) prior to their degradation are questions still under debate. Several proteins, in particular cysteine proteases, have been demonstrated to be specifically expressed during senescence. Their contribution to the general degradation of chloroplast proteins is unclear. The accumulation in intact cells of peptide fragments and inhibitor studies suggest that multiple degradation pathways may exist for stromal proteins and that vacuolar endopeptidases might also be involved under certain conditions. The breakdown of chlorophyll-binding proteins associated with the thylakoid membrane is less well investigated. The degradation of these proteins requires the simultaneous catabolism of chlorophylls. The breakdown of chlorophylls has been elucidated during the last decade. Interestingly, nitrogen present in chlorophyll is not exported from senescencing leaves, but remains within the cells in the form of linear tetrapyrrolic catabolites that accumulate in the vacuole. The degradation pathways for chlorophylls and chloroplast proteins are partially interconnected.
\end{abstract}

Key words: Chlorophyll catabolism, chloroplast, compartmentation, membrane integrity, protein degradation, vacuole.

\section{Introduction}

Senescence represents the final stage of leaf development and is characterized by the transition from nutrient assimilation to nutrient remobilization (Feller and Fischer, 1994; Masclaux et al., 2000). The catabolic processes are well organized on the whole plant level (Noodén, 1988), on the organ level (Feller et al., 1977), on the cellular level (Zeiger and Schwartz, 1982), and on the subcellular level (Matile, 1992). In mesophyll cells, chloroplasts are dismantled in an early phase of senescence, while mitochondria remain functional. Up to $75 \%$ of the nitrogen present in mesophyll cells is located in the chloroplasts (Peoples and Dalling, 1988). Stromal enzymes, mainly Rubisco, represent the major fraction of chloroplast nitrogen. The rate of senescence and the remobilization of leaf nitrogen are related to the nitrogen nutrition status of the plant and on source/sink relations (Crafts-Brandner et al., 1996, 1998; Ono et al., 1999; Masclaux et al., 2000).

\section{Chlorophyll and protein catabolism inside the chloroplasts}

Several lines of evidence support the conclusion that at least the initial steps of chlorophyll and chloroplast protein degradation can occur in the intact organelles. On the other hand, some steps are or might be located outside the plastids (Fig. 1). It must also be considered that alternative catabolic pathways may exist and that they may be compartmentalized in a manner not yet discovered.

\section{Degradation of stromal enzymes}

Regardless of the fate of thylakoid constituents, stromal enzymes are degraded early during senescence leading to the decline of photosynthetic capacity. Enzymes involved in carbon and nitrogen assimilation are lost and the amino acids derived from their catabolism may

\footnotetext{
${ }^{1}$ To whom correspondence should be addressed. Fax: +41313322059. E-mail: urs.feller@ips.unibe.ch
} 


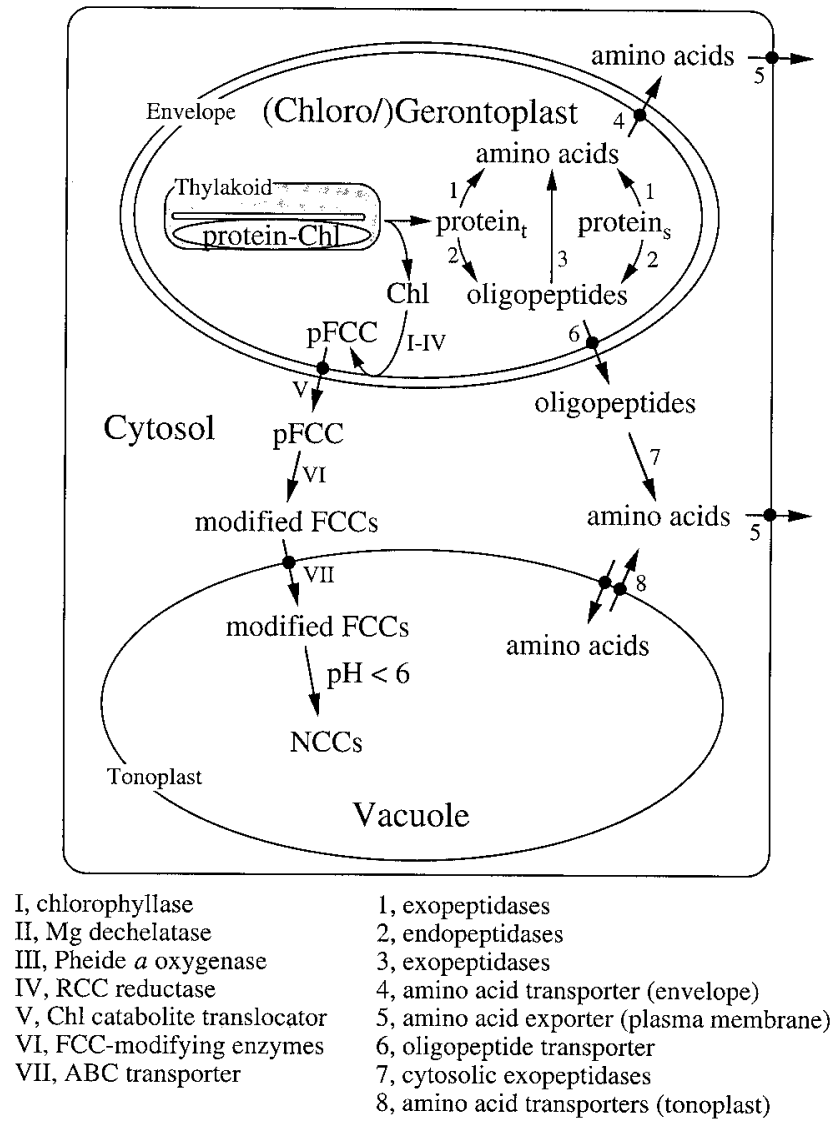

Fig. 1. Pathways for the degradation of $\mathrm{Chl}$ (roman numbers) and of chloroplast proteins (arabic numbers). Protein ${ }_{t}$, thylakoid proteins; protein $_{\mathrm{s}}$, stromal proteins.

be exported via the phloem with or without prior modification (e.g. production of amides from other amino acids). Glutamine synthetase, the key enzyme in the assimilation of ammonia, is present in the chloroplasts and in the cytosol. The plastidial form is lost in cereal leaves in an early phase of senescence, while the cytosolic form remains active longer (Streit and Feller, 1983). Glutamine synthetase is rather susceptible to proteolysis in isolated chloroplasts and it is degraded far more rapidly than Rubisco or other enzymes involved in carbon assimilation (Mitsuhashi and Feller, 1992; Thoenen and Feller, 1998). The cytosolic form of glutamine synthetase was shown to be localized in the vascular bundles of rice leaves (Sakurai et al., 1996). Based on immunological data, a shift in ammonia assimilation from the chloroplast to the cytosol of mesophyll cells of tobacco was suggested recently (Brugière et al., 2000).

It has been reported that stromal enzymes are degraded in isolated pea chloroplasts (Mitsuhashi and Feller, 1992; Thoenen and Feller, 1998). In these studies, the chloroplasts were isolated, incubated under defined conditions and re-isolated from each sample to ensure that only chloroplasts remaining intact throughout the incubation period were analysed. It may be important from a technical point of view to consider that EDTA and DTT (common ingredients in isolation and incubation buffers) can severely interfere with proteolysis in chloroplasts (Roulin and Feller, 1998a, b). DTT inhibits violaxanthin de-epoxidase and ascorbate peroxidase, two enzymes involved in the detoxification of reactive oxygen species in chloroplasts (Neubauer, 1993; Stieger and Feller, 1997). EDTA on the other hand most likely interferes with a proteolytic enzyme depending on divalent cations (Roulin and Feller, 1998b). In contrast to the quite rapid degradation of stromal enzymes such as Rubisco, glutamine synthetase and glutamate synthase observed in intact chloroplasts isolated from mature pea leaves, only a very slow catabolism of the same enzymes was observed after chloroplast lysis (Roulin and Feller, 1997).

The degradation of the predominant stromal protein in $\mathrm{C}_{3}$-plants, Rubisco, has been the subject of several studies (Mitsuhashi et al., 1992; Desimone et al., 1996; Ishida et al., 1997, 1998, 1999). In intact chloroplasts, degradation of Rubisco causes the accumulation of different fragment patterns depending on the specific experimental conditions (e.g. pH, energy status, solute concentrations, radicals) during incubation (Mitsuhashi et al., 1992; Hildbrand et al., 1994; Herrmann and Feller, 1998). It has often been suggested that Rubisco degradation may be initiated by reactive oxygen species (Desimone et al., 1996, 1998; Ishida et al., 1998; Roulin and Feller, 1998a; Stieger and Feller, 1997). A direct (non-enzymic) cleavage of the large subunit of Rubisco into a $37 \mathrm{kDa}$ and a $16 \mathrm{kDa}$ fragment induced by reactive oxygen has been reported (Ishida et al., 1997).

The complete hydrolysis of proteins to free amino acids depends on the action of endo- and exopeptidases (Brouquisse et al., 2001). Endopeptidases are essential for the first cleavage(s) of peptide bonds in a protein and, therefore, also for the initiation of the catabolism of this protein. Several types of endopeptidases have been detected in plastids. Evidence for the involvement of a metalloendopeptidase in stroma protein degradation has been presented by several groups (Bushnell et al., 1993; Roulin and Feller, 1998b). Aminopeptidases are also present in the plastids and may also contribute to the complete degradation of stromal proteins, especially by degrading the peptides generated by endopeptidase activity. On the other hand, carboxypeptidases (vacuolar enzymes) were not detected in intact plastids (Feller and Fischer, 1994, and references therein). Together these data suggest that metalloendopeptidase and aminopeptidases are key enzymes for the degradation of stromal proteins.

The presence of the Clp system in plastids has been reported by several groups during the past few years. 
The Clp protease with the plastome-encoded proteolytic subunit ClpP and the nuclear-encoded ATPase subunit $\mathrm{ClpC}$ was identified in several species at the transcript level and at the protein level (Shanklin et al., 1995; CraftsBrandner et al., 1996, 1998; Weaver et al., 1999). It appears likely that this proteolytic system plays a role in chloroplast development or housekeeping (Shikanai et al., 2001). The Clp protease may also be important for the degradation of polypeptides in the cytochrome $b_{6} f$ complex (Majeran et al., 2000). Hence this proteolytic system is likely to be important mainly before the onset of senescence and the involvement of $\mathrm{Clp}$ in the catabolism of mature proteins during senescence must be questioned. To this end there is no good evidence available for a key regulatory role of $\mathrm{Clp}$ in the remobilization of stromal proteins from senescing leaves.

Protein catabolism in plastids may not only be controlled by the levels of proteolytic activities, but also by the susceptibility of the substrate proteins. Besides catalytic and regulatory properties of an enzyme, its intrinsic susceptibility to proteolytic attack must be considered as a physiologically highly relevant aspect. This type of post-translational control is often overlooked. Plastidial isoforms of glutamine synthetase (Streit and Feller, 1983) and of glutamate pyruvate transaminase (Thomas and Feller, 1993) are far more susceptible to proteolysis than the cytosolic forms. The results indicate that the stroma contains some rather fragile enzymes. Furthermore, stromal enzymes can be protected from degradation by interaction with ligands (Thoenen and Feller, 1998; Khan et al., 1999). For example, in intact pea chloroplasts, plastidial glutamine synthetase is protected from degradation by the inhibitor methionine sulphoximine which is a substrate analogue that binds tightly to the glutamate binding site (Thoenen and Feller, 1998). Rubisco on the other hand is protected against breakdown by trypsin or soluble chloroplast proteases by the natural inhibitor 2 '-carboxy-D-arabinitol 1-phosphate (Khan et al., 1999). Chloroplast enzymes are involved in protein turnover throughout leaf development. It is not known if the proteolytic activities involved in protein turnover are also involved in the net degradation of chloroplast proteins during senescence. It is possible that such catabolic enzymes may function in the initial (reversible) phase of senescence and that other proteolytic systems become more relevant as senescence progresses.

\section{Breakdown of thylakoid-bound proteins}

The morphological analysis of senescing chloroplasts reveals dramatic changes of the thylakoid membrane system. The contact between grana stacks is loosened and, finally, the membranes disappear in conjunction with an increase in the number and size of plastoglobuli.
Concomitant with the disappearance of the membrane system is the degradation of membrane constituents such as lipids, proteins and chlorophyll (Chl) (Matile, 1992). Most important in terms of nitrogen content are the thylakoid-bound apoproteins of chlorophyll, mainly LHCP II. Hence, in addition to Rubisco, degradation of LHCP II is a major contributor to the overall loss of protein during foliar senescence (Matile, 1992).

Unfortunately, thylakoid protein turnover or degradation during senescence has not been studied in great detail. Exceptions are LHCP II and the D1 protein of photosystem II. D1 requires Chl for stable integration into the thylakoid membrane (Mullet et al., 1990) and has an extremely rapid turnover rate in the light (Mattoo et al., 1984). It has been shown that this rapid turnover rate of D1 proceeds into late senescence (Roberts et al., 1987) and is accompanied by the turnover of Chl (Raskin et al., 1995).

LHCP II has been investigated during the course of leaf development and senescence in several species (Hidema et al., 1992). Studies using stay-green genotypes of Festuca pratensis and Phaseolus vulgaris demonstrated that LHCP II degradation requires the simultaneous loss of Chl. In wild types, LHCP II and Rubisco subunits were degraded at similar rates during senescence. By contrast, the mutants which retained most of their Chl into late senescence also retained LHCP II, whereas Rubisco subunits were catabolized as in the wild types (Hilditch et al., 1989; Bachmann et al., 1994).

There are no data available concerning the enzymes responsible for the digestion of thylakoid-bound proteins. The question can be raised whether there are specific proteases that exclusively hydrolyse the apoproteins of Chl. However, it seems more likely that these undefined proteases have a broader substrate specificity. Thus, whether a thylakoid or stromal protein is prone to digestion may be regulated by the accessibility of the particular protein rather than by changes of the proteolytic machinery. There is striking evidence that Chl-binding proteins like LHCP II are stabilized through the insertion of $\mathrm{Chl}$ and proteolysis is prevented as long as the pigment-protein complexes are retained (White and Green, 1987). A net loss of apoproteins during senescence only occurs after the removal and degradation of Chl. In stay-greens where Chl catabolism is blocked, LHCP II remains stabilized and proteolytic cleavage is restricted to a small N-terminal region of the protein that protrudes into the stroma (Thomas and Donnison, 2000). Based on these data, it seems obvious that catabolism of $\mathrm{Chl}$ is a prerequisite for the proteolysis of its apoproteins. Disassembly of pigment-protein complexes causes the release of potentially hazardous $\mathrm{Chl}$ that can cause photo-oxidative damage. Thus, degradation of this photosynthetic pigment is necessary for the remobilization of nitrogen located in the Chl-apoproteins. 


\section{Chlorophyll catabolism in senescing chloroplasts}

The catabolism of Chl during leaf senescence is accompanied by the loss of green colour and is one of the most spectacular phenomena in nature. The breakdown pathway has been nearly completely elucidated during the last decade, starting in 1991 with the first description of a Chl catabolite from barley (Kräutler et al., 1991). More recently, non-fluorescent Chl catabolites (NCCs) have been found in a number of different species (Mühlecker and Kräutler, 1996; Curty and Engel, 1996) and are believed to represent the final breakdown products of $\mathrm{Chl}$ that are deposited in the central vacuole. Chemically they represent tetrapyrroles derived from $\mathrm{Chl}$ by oxygenolytic opening of the porphyrin macrocycle. Hence, the four moles of nitrogen associated with each mole of Chl are not recycled during senescence, but are lost when senescent leaves shed.

Catabolism of $\mathrm{Chl}$ is catalysed by at least five enzymic reactions commonly found in all species that have been investigated. The first four reactions take place in the senescing chloroplasts (gerontoplasts) (Fig. 1) starting with the removal of the phytol chain by chlorophyllase producing chlorophyllide (Chlide). Chlorophyllase, first described by Stoll (Willstätter and Stoll, 1913), is localized in the inner envelope membrane (Matile et al., 1997) and exhibits a rather unusual latency. Thus in vitro, activity can only be measured in the presence of high concentrations of detergents or solvents (Trebitsh et al., 1993). The spatial separation of $\mathrm{Chl}$ and chlorophyllase invokes the necessity of an as yet unknown factor which establishes the physical contact between substrate and enzyme and which could represent a regulator for the initiation of Chl catabolism. Chlorophyllase genes have been recently identified from Arabidopsis, Citrus and Chenopodium (Jakob-Wilk et al., 1999; Tsuchiya et al., 1999) with surprising results: all deduced proteins are soluble and some of them may be extraplastidially located. This fact raises the question whether other subcellular compartments may be involved in the early catabolism of Chl (see below).

$\mathrm{Mg}$-free forms of $\mathrm{Chl}$ have been identified in several plant species during senescence (Ziegler et al., 1988). Using senescent rape cotyledons, considerable quantities of pheophorbide (Pheide) a accumulated, when the subsequent cleavage of the porphyrin macrocycle was inhibited (see below). By contrast, during normal yellowing, Pheide $a$ did not accumulate (Langmeier et al., 1993). Thus, the removal of the central atom, $\mathrm{Mg}$, of Chlide by $\mathrm{Mg}$ dechelatase to yield Pheide was postulated to represent the second enzyme in the Chl catabolic pathway. This activity has not yet been investigated in much detail, but it appears to be associated with a heat stable substance of low molecular weight (Shioi et al., 1996).
The third reaction in the Chl catabolic pathway is most important for leaf yellowing because it is responsible for the loss of green colour. Actually, two enzymes are necessary for the formation of the first identifiable cleavage product of Pheide $a$, a primary fluorescent $\mathrm{Chl}$ catabolite (pFCC). Firstly, Pheide $a$ oxygenase $(\mathrm{PaO})$ opens the porphyrin macrocycle by the introduction of oxygen. This yields a red Chl catabolite (RCC) intermediate that is released from $\mathrm{PaO}$ after a site-specific reduction catalysed by RCC reductase (RCCR) (Rodoni et al., 1997a). RCCR activity has been detected in roots, and is measurable in the stroma at all stages of leaf development (Rodoni et al., 1997a; Wüthrich et al., 2000). By contrast, $\mathrm{PaO}$ is bound to the inner envelope membrane (Matile and Schellenberg, 1996) and its activity is only detectable during senescence (Hörtensteiner et al., 1995). Despite their different locations, it is evident that $\mathrm{PaO}$ and RCCR interact closely during catalysis, and metabolically channel RCC. Both partial reactions use reduced ferredoxin (Fd) as a source for electrons; and reduced $\mathrm{Fd}$ is regenerated either by the pentose phosphate cycle or by photosystem I.

Metal chelation and reconstitution experiments have shown that $\mathrm{PaO}$ is a non-haem iron containing monooxygenase (Hörtensteiner et al., 1998). It is specific for Pheide $a$ and, in vitro, Pheide $b$ acts as a competitive inhibitor. This remarkable specificity is reflected by the NCCs which exclusively are derived from $\mathrm{Chl} a$, suggesting that $\mathrm{Chl} b$ is converted to Chl $a$ prior to entering the $\mathrm{Chl}$ catabolic pathway. Indeed, a Chl $b$-reducing system has recently been described in barley and cucumber, which could be important for Chl $b$ to $a$ conversion during senescence (Ito et al., 1996; Scheumann et al., 1999).

RCCR is a novel reductase that does not require a prosthetic group for the transfer of electrons from $\mathrm{Fd}$ to RCC (S Hörtensteiner, B Kräutler, unpublished data). The properties of RCCR are remarkable as it acts in a stereospecific manner when assayed together with $\mathrm{PaO}$ in vitro. Depending on the source of RCCR, only one of two possible epimers of pFCC occurs (Hörtensteiner et al., 2000; Mühlecker et al., 2000). This stereospecificity is lost when assays are performed with RCCR on its own using artificial RCC as substrate: under this condition, both epimers are formed simultaneously. RCCR has been partially purified from barley and was subsequently cloned from Arabidopsis (Rodoni et al., 1997b; Wüthrich et al., 2000). The identification of accelerated cell death (acd) mutants in Arabidopsis (Greenberg et al., 1994) has led to the isolation of $a c d 2$ that is defective in the RCCR gene (Mach et al., 2001). The accumulation of phototoxic Chl degradation products such as RCC has been suggested to cause the hypersensitive phenotype observed in $a c d 2$, but there are several indications that RCCR may have other as yet undefined functions during plant 
development. Thus, the acd2 phenotype occurs even at presenescent stages of development, i.e. before $\mathrm{PaO}$ activity could cause the accumulation of RCC and, in addition, analysis of RCCR expression revealed the presence of the enzyme not only in senescent leaves, but also in non-green tissues such as roots (Wüthrich et al., 2000).

\section{Interactions between chloroplasts and other subcellular compartments}

Although the first steps in the degradation of chlorophylls and of proteins are catalysed by enzymes present inside the chloroplasts, interactions with other subcellular compartments are also relevant in this context. Catabolites generated inside the chloroplasts may be further metabolized after the release across the chloroplast envelope.

\section{Release of catabolites across the chloroplast envelope and further degradation in other compartments}

When isolated gerontoplasts of barley or oilseed rape were examined for the production of Chl catabolites, FCCs were synthesized in organello when energy was supplied in the form of ATP or glucose-6-phosphate (Matile et al., 1992; Ginsburg et al., 1994). In addition, in the presence of ATP, export of FCCs was observed. The export could not be activated by UTP and required hydrolysis of ATP, indicating that an ATP-dependent transport system at the envelope was responsible for the release of $\mathrm{Chl}$ catabolites from senescent chloroplasts (Matile et al., 1992). The nature of the respective transport protein has not been identified.

After export from gerontoplasts and extraplastidial modification (see below), Chl catabolites are eventually imported into the vacuole by a tonoplast-bound transport system (Fig. 1). The nature of this carrier has been identified as a primary active ATPase (Hinder et al., 1996) of the type of multidrug resistance-associated proteins that are members of the class of ATP-binding cassette transporters (Tommasini et al., 1998).

From the chemical structures of pFCC (Mühlecker et al., 1997) and the final NCCs, two additional reactions commonly occurring in the $\mathrm{Chl}$ catabolic pathway were postulated. First, an ethyl side-chain (C8) of pFCC is hydroxylated, most probably by an as yet undefined P450-dependent hydroxylase. Whether this enzyme is located at the endoplasmatic reticulum, similar to other P450 systems, is unclear. The finding that modified FCCs, in addition to $\mathrm{pFCC}$, are formed within and exported from gerontoplasts (Matile et al., 1992; Ginsburg et al., 1994) suggests that the hydroxylase could also be located inside the chloroplast.
The second modification concerns the conversion of FCCs into NCCs. This tautomerization is a non-enzymic reaction, most probably catalysed by the acidic $\mathrm{pH}$ of the vacuolar sap (S Hörtensteiner, unpublished data).

In addition to these common reactions, there are species-specific modifications of $\mathrm{Chl}$ catabolites that could be postulated based on the chemical structures of the respective NCCs. For example, in oilseed rape, a total of three different NCCs accumulate which differ at the $\mathrm{C} 8$-ethyl side-chain. Whereas it is hydroxylated in $\mathrm{Bn}$-NCC-3 (for a nomenclature of $\mathrm{Chl}$ catabolites see Ginsburg and Matile, 1993), the OH-group is conjugated with malonic acid in Bn-NCC-1 and with glucose in Bn-NCC-2 (Mühlecker and Kräutler, 1996). The formation of $\mathrm{Bn}$-NCC-1 that is catalysed by a malonyltransferase which uses malonyl-coenzyme $\mathrm{A}$ as the co-substrate has been reported (Hörtensteiner, 1998).

There are a number of reports describing the oxidative bleaching of Chl in vitro (Lüthy et al., 1986). However, in all of these reports the respective degradation products identified are not natural derivatives of Chl. The positive correlation of Chl-bleaching activities with senescence (Johnson-Flanagan and Spencer, 1996) does not imply their in vivo contribution to Chl breakdown. An indication that catabolism of $\mathrm{Chl}$ is extraplastidial was supported by the finding of a mass exodus of Chl-containing plastoglobules from senescent soybean chloroplasts (Guiamèt et al., 1999). The combination of extraplastidiallocated chlorophyllase (Tsuchiya et al., 1999) and unspecified vacuolar oxidases has been postulated as an alternative Chl-catabolic pathway (Takamiya et al., 2000). Whether this pathway is important in vivo remains to be shown. It is not likely that a second complete extraplastidial pathway involving the $\mathrm{PaO} / \mathrm{RCCR}$ system exists, as RCCR has been demonstrated to be located in the stroma and encoded by a single copy gene in barley and Arabidopsis (Wüthrich et al., 2000).

Proteolytic activities are also present in the cytosol, in the vacuole, and in the peroxisomes and may function in the degradation of peptides released from chloroplasts (Distefano et al., 1999; Brouquisse et al., 2001). There is no direct proof for such a release of peptides from chloroplasts (Fig. 1), but peptide translocators have been identified in plants (Jamai et al., 1994). Aminopeptidases and oligopeptidases in the cytosol may cleave oligopeptides into free amino acids. The proteasome and other endoproteolytic enzymes are located in the cytosol and may also be involved in the catabolism of larger fragments (Brouquisse et al., 2001). In particular, the $20 \mathrm{~S}$ proteasome may contribute to the degradation of denatured proteins in an ATP-independent manner.

High cysteine endopeptidase and carboxypeptidase levels are present in the vacuole. Increased transcript levels (Buchanan-Wollaston, 1997; Ueda et al., 2000) and increased activities (Feller et al., 1977) of cysteine 
endopeptidases have been observed during senescence. Their function may be restricted to degradation processes occurring after cell death (see below).

\section{Import of nuclear encoded catabolic enzymes into the intact chloroplasts}

There are different lines of evidence for the involvement of extraplastidial components in the intraplastidial degradation of Chl to FCCs during senescence (Fig. 2A). For example, isolated mature chloroplasts are not capable of degrading Chl to FCCs as long as they have not started to senesce. In gerontoplasts, however, FCCs are produced in organello when energy is supplied either from the photosynthetic machinery, by external ATP or glucose-6-phosphate (Matile et al., 1992).

It has been shown that de novo cytoplasmic protein synthesis is required for the induction of Chl catabolism and treatment of excised leaves with inhibitors of nuclear protein biosynthesis inhibits normal yellowing (Ginsburg et al., 1994). With the exception of $\mathrm{PaO}$, all known components of the Chl catabolic pathway are constitutive. Again, cycloheximide-treated senescent barley leaves exhibit significantly reduced $\mathrm{PaO}$ activity, indicating that $\mathrm{PaO}$ is a nuclear encoded protein that is specifically expressed during senescence (Rodoni et al., 1998). In the stay-green mutant Bf 993 of Festuca pratensis, Chlides and Pheide $a$ accumulate due to the absence of $\mathrm{PaO}$ activity (Vicentini et al., 1995). The accumulation of these dephytylated pigments does not occur when senescent leaves of this mutant are treated with protein biosynthesis inhibitors (Thomas et al., 1989). This suggests that activity of a nuclear-encoded enzyme is required prior to the interaction of chlorophyllase with Chl.
Chlorophyllase and RCCR are nuclear-encoded enzymes which contain transit peptides directing the respective proteins into the chloroplasts (Jakob-Wilk et al., 1999; Wüthrich et al., 2000). In addition, ATPdependent import into isolated chloroplasts and processing of the precursor protein has been demonstrated for RCCR (Wüthrich et al., 2000). All in all, it is clear that Chl breakdown is dependent on the import of several extraplastidial components.

\section{Degradation of chloroplast vesicles or entire chloroplasts after import into the vacuole?}

Evidence for an autophagic nature of vacuoles has largely been documented by electron micrographic studies. These studies show cytoplasmic structures located within vacuoles, and the results were interpreted as evidence for the engulfment of cytosolic material by the tonoplast and subsequent invagination and budding off into the vacuole (reviewed in Matile, 1975). There are justified doubts concerning this concept of autophagic vacuoles, i.e. possible artefacts due to improper tissue fixation. In addition, serial sections clearly demonstrating the invagination process are largely missing (Matile, 1997).

Evidence for vacuolar autophagy of senescing chloroplasts is not convincing. No obvious transfer of plastid material (e.g. in the form of vesicles) or of entire chloroplasts into the vacuole (Fig. 2B) has been demonstrated by electron microscopy (Matile, 1992, 1997). In addition, in tobacco it has been shown that gerontoplasts remain fully intact during leaf senescence and are able to redifferentiate into chloroplasts during a cytokinin-induced regreening of decapitated plants (Zavaleta-Mancera et al., 1999). A recent exception is a report that describes a mass
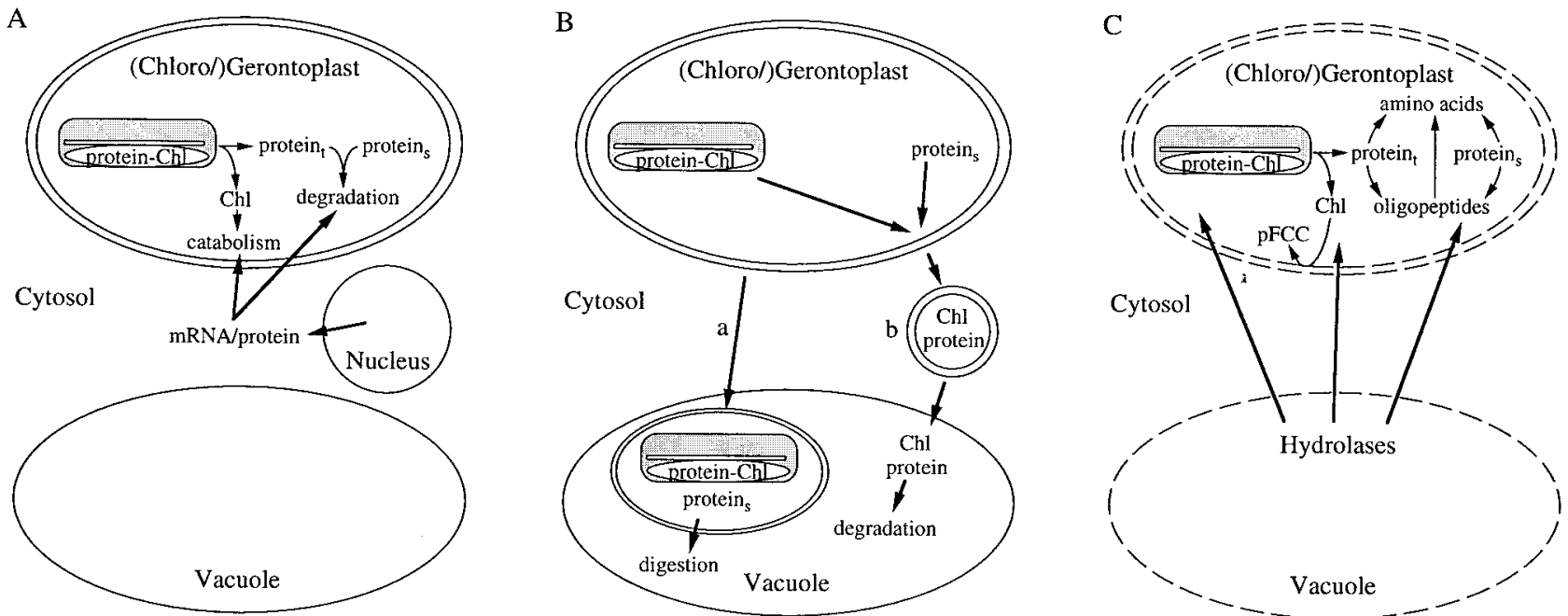

Fig. 2. Extraplastidial contributions to the degradation of chloroplast constituents. (A) Involvement of nuclear-encoded enzymes in the degradation of proteins and of $\mathrm{Chl}$ inside the chloroplast. (B) Hypothetical model for the catabolism of chloroplast-derived components in the vacuole after a transfer of entire chloroplasts (a) or of chloroplast vesicles (b). (C) Degradation of chloroplast constituents by extraplastidial enzymes after loss of membrane intactness. Protein ${ }_{t}$, thylakoid-bound proteins; protein $_{\mathrm{s}}$, stromal proteins. 
exodus of Chl-containing plastoglobules from senescent chloroplasts (Guiamét et al., 1999). Together with the identification of chlorophyllase genes which imply an extraplastidic (vacuolar?) location (Tsuchiya et al., 1999) this was interpreted in terms of an alternative Chl degradation pathway located outside the plastid (Takamiya et al., 2000). Whether such a system could also participate in the metabolism of chloroplast proteins, for example, by delivering proteins to cytosolic or vacuolar proteases, remains to be demonstrated.

Autophagy of entire chloroplasts during leaf senescence would cause a continuous decrease in the number of plastids per mesophyll cell. Yet, assessments of chloroplast numbers in mesophyll protoplasts or cross-sections of senescent leaves have demonstrated that the number of plastids remains constant until late in senescence, whereas plastid markers such as Rubisco or Chl decrease (Martinoia et al., 1983). These observations strongly suggest that $\mathrm{Chl}$ and chloroplast proteins disappear through degradation within the intact plastids without a significant loss of gerontoplast numbers.

\section{Degradation after loss of membrane intactness}

Vacuoles have a lysosomal character as documented by the presence of a large number of different hydrolases such as proteases, nucleases, phosphatases, and glucosidases. Most of these enzymes have an acidic $\mathrm{pH}$ optimum and are rather unspecific enzymes (Boller and Wiemken, 1986). The potential of vacuolar hydrolases for the digestion of cellular constituents is demonstrated by the rapid digestion of proteins and nucleic acids after artificial disruption of the subcellular organization. Thus, in vivo, if cellular components are exposed to vacuolar hydrolases, the process must be tightly regulated. As outlined above, evidence for import into and subsequent digestion of cytoplasmic or plastidial constituents inside the vacuole during senescence is not shown. Despite this, vacuolar hydrolases, and proteases in particular, have been shown to be expressed during senescence (Buchanan-Wollaston, 1997). Their function has not been analysed biochemically, but most probably it is associated with digestion processes occurring after the rupture of the tonoplast at the end of senescence, i.e. during autolysis (Fig. 2C).

This process, also called apoptosis or programmed cell death (PCD), is genetically regulated and has been described for many developmental processes such as formation of tracheary elements in Zinnia elegans (Fukuda, 1996). As for senescence, new hydrolases, among them a cysteine protease, are highly expressed shortly before autolysis is initiated. It is probable that during PCD the vacuolar hydrolases are responsible for the digestion of all remaining subcellular constituents. This would include components of the mitochondria that, during senescence, remain structurally and functionally intact (Matile, 1992), but could also include the complete degradation of undigested gerontoplast constituents (Matile, 1997).

Cysteine endopeptidases are present in the vacuole, but a role in protein degradation in intact chloroplasts has not been demonstrated unambiguously so far. However, vacuolar enzymes may act on stromal proteins after a loss of membrane intactness. The following observations may support this idea. Under low light and low $\mathrm{CO}_{2}$, a $50 \mathrm{kDa}$ fragment of the large subunit of Rubisco (LS) accumulated in wheat leaf segments (Fig. 3), while this fragment was absent in samples of intact plants under $\mathrm{N}$-deprivation or in segments exposed to high light (data not shown). The $50 \mathrm{kDa}$ fragment was shown to be generated by the removal of the $\mathrm{N}$-terminus from intact LS, since it was detected by antibodies raised against the denatured LS, but not by antibodies raised against the $\mathrm{N}$-terminus of LS (Thoenen, 2000). By contrast, isolated chloroplasts accumulate a series of fragments in the range of $30-50 \mathrm{kDa}$. These fragments still contain the original $\mathrm{N}$-terminus, indicating that they were produced by other catabolic steps than the $50 \mathrm{kDa}$ fragment mentioned here. In addition, the $50 \mathrm{kDa}$ fragment was formed while the subunit was still integrated in the holoenzyme complex and the cleavage was inhibited by E-64, a cysteine protease inhibitor (Thoenen, 2000). The Rubisco fragment
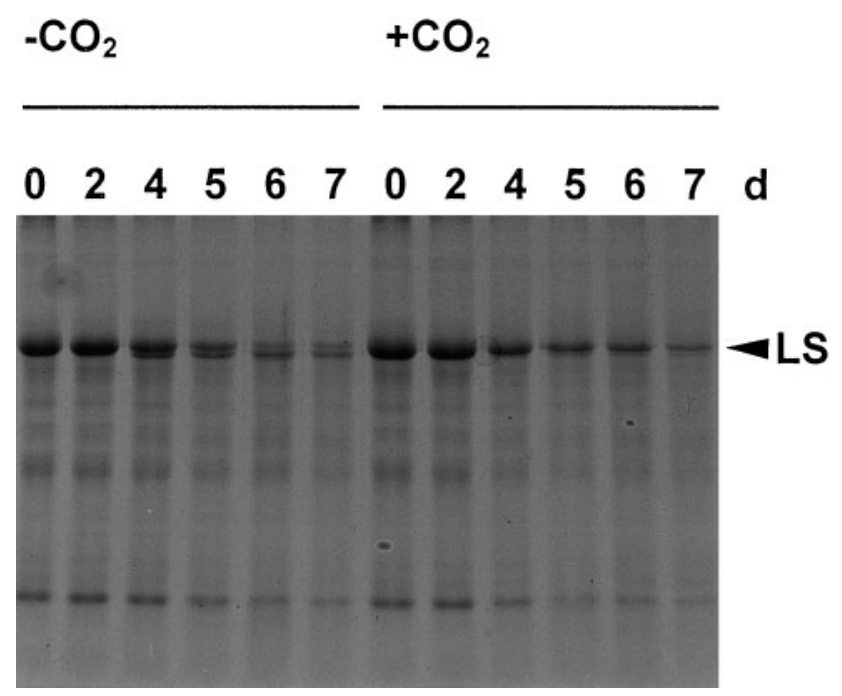

Fig. 3. Accumulation of a $50 \mathrm{kDa}$ fragment of the large subunit of Rubisco (LS) in $\mathrm{CO}_{2}$-free air. Wheat leaf segments floating on nutrient solution (Hildbrand et al., 1994) were incubated in Erlenmeyer flasks in permanent light (photosynthetic active radiation: $50 \mu \mathrm{mol} \mathrm{m}^{-2} \mathrm{~s}^{-1}$ ). The flasks were either bubbled through with $\mathrm{CO}_{2}$-free air $\left(-\mathrm{CO}_{2}\right)$ or with ambient air $\left(+\mathrm{CO}_{2}\right)$. Samples were taken after 0, 2, 4, 5, 6, and $7 \mathrm{~d}$ and analysed by SDS-PAGE followed by staining with Coomassie Brilliant Blue R250. Each lane was loaded with $5 \mu$ l extract containing three $5 \mathrm{~cm}$ segments per $\mathrm{ml}^{-1}$. The additional band below LS was cross-reactive with antibodies against LS (data not shown) and was produced during incubation in $\mathrm{CO}_{2}$-free air, but not in ambient air. 
was also formed during incubation of wheat leaf extracts. However, it was not detected in wheat leaf segments with high carbohydrate levels or in isolated pea chloroplasts (Roulin and Feller, 1998b).

The involvement of vacuolar enzymes in a progressive amino-terminal degradation of the large subunit of Rubisco in French bean leaves has been proposed earlier (Yoshida and Minamikawa, 1996). However, conditions under which vacuolar hydrolases may contact stromal proteins are not clear, although the release of vacuolar enzymes into other compartments after membrane rupture represents a likely possibility (especially during the final phase of senescence). An extracellular metalloproteinase may be important for the degradation of proteins in the extracellular matrix and may also contribute to the degradation of proteins from other compartments after the loss of membrane intactness (Delorme et al., 2000).

\section{Conclusions}

The initial steps in the degradation of chlorophylls and of chloroplast proteins can occur in the intact organelles. Chloroplasts isolated from mature pea leaves are able to degrade stromal proteins including the predominant enzyme Rubisco. On the other hand, degradation of chlorophylls and of major membrane proteins depends on the synthesis and import of at least one nuclear-encoded catabolic enzyme, $\mathrm{PaO}$, at the onset of senescence. The fact that chloroplast constituents can be degraded in the intact organelles does not necessarily mean that they are under all circumstances degraded while the chloroplast envelope is still intact. It appears possible that different environmental situations (e.g. energy supply) affect not only the velocity, but also the compartmentation of the catabolism of chloroplast proteins and chlorophylls. The initial (reversible) phase of senescence may differ considerably from the final (irreversible) phase. Vacuolar and other extraplastidial enzymes may contact chloroplast constituents after membrane rupture, whilst before senescence or during early senescence these catabolic enzymes are separated from stroma and thylakoid components by membranes. Based on current information, the control of membrane intactness has emerged as a key issue of senescence regulation.

\section{Acknowledgements}

The authors thank Beat Herrmann for the samples of wheat leaf segments, Regina Hölzer for the careful analyses of the samples, Steven $\mathbf{J}$ Crafts-Brandner for improving the style of the manuscript, and the Swiss National Science Foundation for financial support.

\section{References}

Bachmann A, Fernándes-López J, Ginsburg S, Thomas H, Bouwkamp JC, Solomos T, Matile P. 1994. Stay-green genotypes of Phaseolus vulgaris L.: chloroplast proteins and chlorophyll catabolites during foliar senescence. New Phytologist 126, 593-600.

Boller T, Wiemken A. 1986. Dynamics of vacuolar compartmentation. Annual Review of Plant Physiology 37, 137-164.

Brouquisse R, Masclaux C, Feller U, Raymond P. 2001. Protein hydrolysis and nitrogen remobilisation in plant life and senescence. In: Lea PJ, Morot-Gaudry J-F, eds. Plant nitrogen. Berlin: Springer-Verlag, 275-293.

Brugière N, Dubois F, Masclaux C, Sangwan RS, Hirel B. 2000. Immunolocalization of glutamine synthetase in senescing tobacco (Nicotiana tabacum L.) leaves suggests that ammonia assimilation is progressively shifted to the mesophyll cytosol. Planta 211, 519-527.

Buchanan-Wollaston V. 1997. The molecular biology of leaf senescence. Journal of Experimental Botany 48, 181-199.

Bushnell TP, Bushnell D, Jagendorf AT. 1993. A purified zinc protease of pea chloroplasts, EP1, degrades the large subunit of ribulose-1,5-bisphosphate carboxylase/oxygenase. Plant Physiology 103, 585-591.

Crafts-Brandner SJ, Hölzer R, Feller U. 1998. Influence of nitrogen deficiency on senescence and the amounts of RNA and proteins in wheat leaves. Physiologia Plantarum 102 , 192-200.

Crafts-Brandner SJ, Klein RR, Klein P, Hölzer R, Feller U.1996. Coordination of protein and mRNA abundances of stromal enzymes and mRNA abundances of the Clp protease subunits during senescence of Phaseolus vulgaris (L.) leaves. Planta 200, 312-318.

Curty C, Engel N. 1996. Detection, isolation and structure elucidation of a chlorophyll $a$ catabolite from autumnal senescent leaves of Cercidiphyllum japonicum. Phytochemistry 42, 1531-1536.

Delorme VGR, McCabe PF, Kim D-J, Leaver CJ. 2000. A matrix metalloproteinase gene is expressed at the boundary of senescence and programmed cell death in cucumber. Plant Physiology 123, 917-927.

Desimone M, Henke A, Wagner E. 1996. Oxidative stress induces partial degradation of the large subunit of ribulose1, 5-bisphosphate carboxylase/oxygenase in isolated chloroplasts of barley. Plant Physiology 111, 789-796.

Desimone M, Wagner E, Johanningmeier U. 1998. Degradation of active-oxygen modified ribulose-1,5-bisphosphate carboxylase/oxygenase by chloroplastic proteases requires ATP-hydrolysis. Planta 205, 459-466.

Distefano S, Palma JM, McCarthy I, del Rio LA. 1999. Proteolytic cleavage of plant proteins by peroxisomal endoproteases from senescent pea leaves. Planta 209, 308-313.

Feller U, Fischer A. 1994. Nitrogen metabolism in senescing leaves. Critical Reviews in Plant Sciences 13, 241-273.

Feller UK, Soong T-ST, Hageman RH. 1977. Leaf proteolytic activities and senescence during grain development of field-grown corn (Zea mays L.). Plant Physiology 59, 290-294.

Fukuda H. 1996. Xylogenesis: initiation, progression, and cell death. Annual Review of Plant Physiology and Plant Molecular Biology 47, 299-325.

Ginsburg S, Matile P. 1993. Identification of catabolites of chlorophyll porphyrin in senescent rape cotyledons. Plant Physiology 102, 521-527. 
Ginsburg S, Schellenberg M, Matile P. 1994. Cleavage of chlorophyll-porphyrin. Requirement for reduced ferredoxin and oxygen. Plant Physiology 105, 545-554.

Greenberg JT, Guo A, Klessig DF, Ausubel FM. 1994. Programmed cell death in plants: a pathogen-triggered response activated coordinately with multiple defense functions. Cell 77, 551-563.

Guiamét JJ, Pichersky E, Noodén LD. 1999. Mass exodus from senescing soybean chloroplasts. Plant Cell Physiology 40, 986-992.

Herrmann B, Feller U. 1998. $\mathrm{CO}_{2}$, light and temperature influence senescence and protein degradation in wheat leaf segments. Physiologia Plantarum 103, 320-326.

Hidema J, Makino A, Kurita Y, Mae T, Ojima K. 1992. Changes in the levels of chlorophyll and light-harvesting chlorophyll $a / b$ proteins of PSII in rice leaves aged under different irradiances from full expansion through senescence. Plant Cell Physiology 33, 1209-1214.

Hilditch PI, Thomas H, Thomas BJ, Rogers LJ. 1989. Leaf senescence in a non-yellowing mutant of Festuca pratensis: proteins of photosystem II. Planta 177, 265-272.

Hildbrand M, Fischer A, Feller U. 1994. Protein catabolism in bean leaf discs: accumulation of a soluble fragment of ribulose-1,5-bisphosphate carboxylase/oxygenase under oxygen deficiency. Journal of Experimental Botany 45, 1197-1204.

Hinder B, Schellenberg M, Rodoni S, Ginsburg S, Vogt E, Martinoia E, Matile P, Hörtensteiner S. 1996. How plants dispose of chlorophyll catabolites. Directly energized uptake of tetrapyrrolic breakdown products into isolated vacuoles. Journal of Biological Chemistry 271, 27233-27236.

Hörtensteiner S. 1998. NCC malonyltransferase catalyses the final step in chlorophyll breakdown in rape (Brassica napus). Phytochemistry 49, 953-956.

Hörtensteiner S, Rodoni S, Schellenberg M, Vicentini F, Nandi OI, Qiu Y-L, Matile P. 2000. Evolution of chlorophyll degradation: the significance of RCC reductase. Plant Biology 2, 63-67.

Hörtensteiner S, Vicentini F, Matile P. 1995. Chlorophyll breakdown in senescent cotyledons of rape, Brassica napus L.: enzymatic cleavage of pheophorbide $a$ in vitro. New Phytologist 129, 237-246.

Hörtensteiner S, Wüthrich KL, Matile P, Ongania K-H, Kräutler B. 1998. The key step in chlorophyll breakdown in higher plants. Cleavage of pheophorbide $a$ macrocycle by a monooxygenase. Journal of Biological Chemistry 271, 15335-15339.

Ishida H, Makino A, Mae T. 1999. Fragmentation of the large subunit of ribulose-1,5-bisphosphate carboxylase by reactive oxygen species occurs near Gly-329. Journal of Biological Chemistry 274, 5222-5226.

Ishida H, Nishimori Y, Sugisawa M, Makino A, Mae T. 1997. The large subunit of ribulose-1,5-bisphosphate carboxylase oxygenase is fragmented into $37 \mathrm{kDa}$ and $16 \mathrm{kDa}$ polypeptides by active oxygen in the lysates of chloroplasts from primary leaves of wheat. Plant Cell Physiology 38, 471-479.

Ishida H, Shimizu S, Makino A, Mae T. 1998. Light-dependent fragmentation of the large subunit of ribulose-1,5bisphosphate carboxylase/oxygenase in chloroplasts isolated from wheat. Planta 204, 305-309.

Ito H, Ohysuka T, Tanaka A. 1996. Conversion of chlorophyll $b$ to chlorophyll $a$ via 7-hydroxymethyl chlorophyll. Journal of Biological Chemistry 271, 1475-1479.

Jakob-Wilk D, Holland D, Goldschmidt EE, Riov J, Eyal Y. 1999. Chlorophyll breakdown by chlorophyllase: isolation and functional expression of the Chlasel gene from ethylenetreated Citrus fruit and its regulation during development. The Plant Journal 20, 653-661.
Jamai A, Chollet J, Delrot S. 1994. Proton-peptide cotransport in broad bean leaf tissues. Plant Physiology 106, 1023-1031.

Johnson-Flanagan AM, Spencer MS. 1996. Chlorophyllase and peroxidase activity during degreening of mature canola (Brassica napus) and mustard (Brassica juncea) seed. Physiologia Plantarum 97, 353-359.

Khan S, Andralojc PJ, Lea PJ, Parry MAJ. 1999. 2' -CarboxyD-arabinitol 1-phosphate protects ribulose 1,5-bisphosphate carboxylase/oxygenase against proteolytic breakdown. European Journal of Biochemistry 266, 840-847.

Kräutler B, Jaun B, Bortlik K-H, Schellenberg M, Matile P. 1991. On the enigma of chlorophyll degradation: the constitution of a secoporphinoid catabolite. Angewandte Chemie International Edition in English 30, 1315-1318.

Langmeier M, Ginsburg S, Matile P. 1993. Chlorophyll breakdown in senescent leaves: demonstration of $\mathrm{Mg}$-dechelatase activity. Physiologia Plantarum 89, 347-353.

Lüthy B, Matile P, Thomas H. 1986. Properties of linolenic acid-dependent chlorophyll oxidation activity in thylakoid membranes. Journal of Plant Physiology 123, 203-209.

Mach JM, Castillo A, Hoogstraten R, Greenberg JT. 2001. The Arabidopsis accelerated cell death gene ACD2 encodes red chlorophyll catabolite reductase and suppresses the spread of disease symptoms. Proceedings of the National Academy of Sciences, USA 98, 771-776.

Majeran W, Wollmann F-A, Vallon O. 2000. Evidence for a role of $\mathrm{ClpP}$ in the degradation of the chloroplast cytochrome $\mathrm{b}_{6} \mathrm{f}$ complex. The Plant Cell 12, 137-149.

Martinoia E, Heck U, Dalling MJ, Matile P. 1983. Changes in chloroplast number and chloroplast constituents in senescing barley leaves. Biochemie und Physiologie der Pflanzen 178, 147-155.

Masclaux C, Valadier M-H, Brugière N, Morot-Gaudry J-F, Hirel B. 2000. Characterization of the sink/source transition in tobacco (Nicotiana tabacum L.) shoots in relation to nitrogen management and leaf senescence. Planta 211, 510-518.

Matile P. 1975. The lytic compartment of plant cells. Cell biology monographs. Volume 1. Berlin: Springer.

Matile P. 1992. Chloroplast senescence. In: Baker NR, Thomas $\mathrm{H}$, eds. Crop photosynthesis: spatial and temporal determinants. Amsterdam: Elsevier, 413-440.

Matile P. 1997. The vacuole and cell senescence. In: Callow JA, ed. Advances in botanical research, Vol. 25. San Diego: Academic Press, 87-112.

Matile P, Schellenberg M. 1996. The cleavage of pheophorbide $a$ is located in the envelope of barley gerontoplasts. Plant Physiology and Biochemistry 34, 55-59.

Matile P, Schellenberg M, Peisker C. 1992. Production and release of a chlorophyll catabolite in isolated senescent chloroplasts. Planta 187, 230-235.

Matile P, Schellenberg M, Vicentini F. 1997. Localization of chlorophyllase in the chloroplast envelope. Planta 201, 96-99.

Mattoo AK, Hoffman-Falk H, Marder JB, Edelman M. 1984. Regulation of protein metabolism: coupling of photosynthetic electron transport to in vivo degradation of the rapidly metabolized 32-kilodalton protein of the chloroplast membranes. Proceedings of the National Academy of Sciences, USA 81, 1380-1384.

Mitsuhashi W, Crafts-Brandner SJ, Feller U. 1992. Ribulose1,5-bisphosphate carboxylase/oxygenase degradation in isolated pea chloroplasts incubated in the light or in the dark. Journal of Plant Physiology 139, 653-658.

Mitsuhashi W, Feller U. 1992. Effects of light and external solutes on the catabolism of nuclear-encoded stromal proteins in intact chloroplasts isolated from pea leaves. Plant Physiology 100, 2100-2105. 
Mühlecker W, Kräutler B. 1996. Breakdown of chlorophyll: constitution of non-fluorescing chlorophyll catabolites from senescent cotyledons of the dicot rape. Plant Physiology and Biochemistry 34, 61-75.

Mühlecker W, Kräutler B, Moser D, Matile P, Hörtensteiner S. 2000. Breakdown of chlorophyll: a fluorescent chlorophyll catabolite from sweet pepper (Capsicum annuum). Helvetica Chimica Acta 83, 278-286.

Mühlecker W, Ongania K-H, Kräutler B, Matile P, Hörtensteiner S. 1997. Tracking down chlorophyll breakdown in plants: elucidation of the constitution of a fluorescent chlorophyll catabolite. Angewandte Chemie International Edition in English 36, 401-404.

Mullet JE, Gamble-Klein P, Klein RR. 1990. Chlorophyll regulates accumulation of the plastid-encoded chlorophyll apoproteins CP43 and D1 by increasing apoprotein stability. Proceedings of the National Academy of Sciences, USA 87, 4038-4042.

Neubauer C. 1993. Multiple effects of dithiothreitol on nonphotochemical fluorescence quenching in intact chloroplasts. Plant Physiology 103, 575-583.

Noodén LD. 1988. Whole plant senescence. In: Noodén LD, Leopold AC, eds. Senescence and aging in plants. San Diego: Academic Press, 391-439.

Ono K, Ishimaru K, Aoki N, Ohsugi R. 1999. Transgenic rice with low sucrose-phosphate synthase activities retain more soluble protein and chlorophyll during flag leaf senescence. Plant Physiology and Biochemistry 37, 949-953.

Peoples MB, Dalling MJ. 1988. The interplay between proteolysis and amino acid metabolism during senescence and nitrogen reallocation. In: Noodén LD, Leopold AC, eds. Senescence and aging in plants. San Diego: Academic Press, 181-217.

Raskin VI, Fleminger D, Marder JB. 1995. Integration and turnover of photosystem II pigment. In: Mathis P, ed. Photosynthesis: from light to biosphere, Vol. III. Amsterdam: Kluwer, 945-948.

Roberts DR, Thompson JE, Dumbroff EB, Gepstein S, Mattoo AK. 1987. Differential changes in the synthesis and steady-state levels of the thylakoid proteins during bean leaf senescence. Plant Molecular Biology 9, 343-353.

Rodoni S, Mühlecker W, Anderl M, Kräutler B, Moser D, Thomas H, Matile P, Hörtensteiner S. 1997a. Chlorophyll breakdown in senescent chloroplasts. Cleavage of pheophorbide $a$ in two enzymic steps. Plant Physiology 115, 669-676.

Rodoni S, Vicentini F, Schellenberg M, Matile P, Hörtensteiner S. 1997b. Partial purification and characterization of red chlorophyll catabolite reductase, a stromal protein involved in chlorophyll breakdown. Plant Physiology 115, 677-682.

Rodoni S, Schellenberg M, Matile P. 1998. Chlorophyll breakdown in senescing barley leaves as correlated with pheophorbide $a$ oxygenase activity. Journal of Plant Physiology 152, 139-144.

Roulin S, Feller U. 1997. Light-induced proteolysis of stromal proteins in pea (Pisum sativum L.) chloroplasts: requirement for intact organelles. Plant Science 128, 31-41.

Roulin S, Feller U. 1998a. Dithiothreitol triggers photooxidative stress and fragmentation of the large subunit of ribulose-1,5-bisphosphate carboxylase/oxygenase in intact pea chloroplasts. Plant Physiology and Biochemistry 36, 849-856.

Roulin S, Feller U. 1998b. Light-independent degradation of stromal proteins in intact chloroplasts isolated from Pisum sativum L. leaves: requirement for divalent cations. Planta 205, 297-304.
Sakurai N, Hayakawa T, Nakamura T, Yamaya T. 1996. Changes in the cellular localization of cytosolic glutamine synthetase protein in vascular bundles of rice leaves at various stages of development. Planta 200, 306-311.

Scheumann V, Schoch S, Rüdiger W. 1999. Chlorophyll $b$ reduction during senescence of barley seedlings. Planta 209, $364-370$

Shanklin J, Dewitt ND, Flanagan JM. 1995. The stroma of higher plant plastids contain $\mathrm{ClpP}$ and $\mathrm{ClpC}$, functional homologs of Escherichia coli $\mathrm{ClpP}$ and $\mathrm{ClpA}$ : an archetypal two-component ATP-dependent protease. The Plant Cell 7, $1713-1722$.

Shikanai T, Shimizu K, Ueda K, Nishimura Y, Kuroiwaa T, Hashimoto T. 2001. The chloroplast clpP gene, encoding for a proteolytic subunit of ATP-dependent protease, is indispensable for chloroplast development in tobacco. Plant Cell Physiology 42, 264-273.

Shioi Y, Tomita N, Tsuchiya T, Takamiya K. 1996. Conversion of chlorophyllide to pheophorbide by Mg-dechelating substance in extracts of Chenopodium album. Plant Physiology and Biochemistry 34, 41-47.

Stieger PA, Feller U. 1997. Requirements for the lightstimulated degradation of stromal proteins in isolated pea (Pisum sativum L.) chloroplasts. Journal of Experimental Botany 48, 1639-1645.

Streit L, Feller U. 1983. Changing activities and different resistance to proteolytic activity of two forms of glutamine synthetase in wheat leaves during senescence. Physiologie Végétale 21, 103-108.

Takamiya K-I, Tsuchiya T, Ohta H. 2000. Degradation pathway(s) of chlorophyll: what has gene cloning revealed? Trends in Plant Science 10, 426-431.

Thoenen M. 2000. Influence of environmental conditions and of carbohydrate levels on senescence and protein catabolism in wheat leaves. PhD thesis. University of Bern.

Thoenen M, Feller U. 1998. Degradation of glutamine synthetase in intact chloroplasts isolated from pea (Pisum sativum) leaves. Australian Journal of Plant Physiology 25, 279-286.

Thomas H, Bortlik K-H, Rentsch D, Schellenberg M, Matile P. 1989. Catabolism of chlorophyll in vivo: significance of polar chlorophyll catabolites in a non-yellowing senescence mutant of Festuca pratensis Huds. New Phytologist 111, 3-8.

Thomas H, Feller U. 1993. Leaf development in Lolium temulentum: differential susceptibility of transaminase isoenzymes to proteolysis. Journal of Plant Physiology 142, $37-42$.

Thomas H, Donnison I. 2000. Back from the brink: plant senescence and its reversibility. In: Bryant JA, Hughes SG, Garland JM, eds. Programmed cell death in animals and plants. Oxford: Bios, 149-162.

Tommasini R, Vogt E, Fromenteau M, Hörtensteiner S, Matile P, Amrhein N, Martinoia E. 1998. An ABC transporter of Arabidopsis thaliana has both glutathione-conjugate and chlorophyll catabolite transport activity. The Plant Journal 13, 773-780.

Trebitsh T, Goldschmidt EE, Riov J. 1993. Ethylene induces de novo synthesis of chlorophyllase, a chlorophyll degrading enzyme, in Citrus fruit peel. Proceedings of the National Academy of Sciences, USA 90, 9441-9445.

Tsuchiya T, Ohta H, Okawa K, Iwamatsu A, Shimada H, Matsuda T, Takamiya K. 1999. Cloning of chlorophyllase, the key enzyme in chlorophyll degradation: finding of a lipase motif and the induction by methyl jasmonate. Proceedings of the National Academy of Sciences, USA 96, $15362-15367$. 
Ueda T, Seo S, Ohashi Y, Hashimoto J. 2000. Circadian and senescence-enhanced expression of a tobacco cysteine protease gene. Plant Molecular Biology 44, 649-657.

Vicentini F, Hörtensteiner S, Schellenberg M, Thomas H, Matile P. 1995. Chlorophyll breakdown in senescent leaves: identification of the biochemical lesion in a staygreen genotype of Festuca pratensis Huds. New Phytologist 129, 247-252.

Weaver LM, Froehlich JE, Amasino RM. 1999. Chloroplasttargeted ERD1 protein declines but its mRNA increases during senescence in Arabidopsis. Plant Physiology 119, 1209-1216.

White MJ, Green BR. 1987. Polypeptides belonging to each of the three major chlorophyll $a+b$ protein complexes are present in a chlorophyll-b-less barley mutant. European Journal of Biochemistry 165, 531-535.

Willstätter R, Stoll A. 1913. Die Wirkungen der Chlorophyllase. In: Willstätter R, Stoll A, eds. Untersuchungen über Chlorophyll. Berlin: Springer, 172-187.
Wüthrich KL, Bovet L, Hunziker PE, Donnison IS, Hörtensteiner S. 2000. Molecular cloning, functional expression and characterization of RCC reductase involved in chlorophyll catabolism. The Plant Journal 21, 189-198.

Yoshida T, Minamikawa T. 1996. Successive amino terminal proteolysis of the large subunit of ribulose-1,5-bisphosphate carboxylase/oxygenase by vacuolar enzymes from French bean leaves. European Journal of Biochemistry 238, 317-324.

Zavaleta-Mancera HA, Thomas BJ, Thomas H, Scott IM. 1999. Regreening of senescent Nicotiana leaves. II. Redifferentiation of plastids. Journal of Experimental Botany 50, 1683-1689.

Zeiger E, Schwartz A. 1982. Longevity of guard cell chloroplasts in falling leaves: implication for stomatal function and cellular aging. Science 218, 690-682.

Ziegler R, Blaheta A, Guha N, Schönegge B. 1988. Enzymatic formation of pheophorbide and pyropheophorbide during chlorophyll degradation in a mutant of Chlorella fusca SHIRIA et KRAUS. Journal of Plant Physiology 132, 327-332. 